Global Sustainability

cambridge.org/sus

\title{
Perspective: a healthy planet for healthy people - Erratum
}

Paul Ekins and Joyeeta Gupta

\section{Erratum}

Cite this article: Ekins P, Gupta J (2019). Perspective: a healthy planet for healthy people - Erratum. Global Sustainability 2, e23, 1-1. https://doi.org/10.1017/sus.2019.20

(c) The Author(s) 2019. This is an Open Access article, distributed under the terms of the Creative Commons Attribution licence (http:// creativecommons.org/licenses/by/4.0/), which permits unrestricted re-use, distribution, and reproduction in any medium, provided the original work is properly cited.

\section{CAMBRIDGE UNIVERSITY PRESS}

DOI: https://doi.org/10.1017/sus.2019.17, published online by Cambridge University Press 28 October 2019.

The original version of this article contained a number of errors which are detailed below. The publisher apologises for these errors.

Page 1, Technical abstract, lines 5 and 6 should read ...Global Environment Outlook...

Page 4, final line, left column should read ...(Schandl et al., 2016)...

Page 6, line 7 should read ...(BSDC, 2012)...

Page 7, sixth reference, left column should read ...BSDC (2012)...

Page 8, sixth reference, right column should read ...Schandl, H.,...

\section{Reference}

Ekins, P. \& Gupta, J. (2019). Perspective: a healthy planet for healthy people. Global Sustainability, 2, e20, 1-9. doi:10.1017/sus.2019.17 